\title{
'Active Surfaces' as Possible Functional Systems in Detection and Chemical (Bio) Reactivity
}

\author{
Catherine E. Housecroft ${ }^{\star a}$, Cornelia G. Palivan ${ }^{b}$, Karl Gademann ${ }^{c}$, Wolfgang Meier , \\ Michel Calame de, Viktoria Mikhalevich ${ }^{b}$, Xiaoyan Zhang ${ }^{b}$, Ellen Pielc, Mathieu Szponarskic, \\ Alexandra Wieslera, Angelo Lanzilotto ${ }^{a}$, Edwin C. Constable ${ }^{a}$, Axel Fanget ${ }^{d}$, and Ralph L. Stoop ${ }^{d}$
}

\begin{abstract}
This article presents design strategies to demonstrate approaches to generate functionalized surfaces which have the potential for application in molecular systems; sensing and chemical reactivity applications are exemplified. Some applications are proven, while others are still under active investigation. Adaptation and extension of our strategies will lead to interfacing of different type of surfaces, specific interactions at a molecular level, and possible exchange of signals/cargoes between them. Optimization of the present approaches from each of five research groups within the NCCR will be directed towards expanding the types of functional surfaces and the properties that they exhibit.
\end{abstract}

Keywords: Functional systems · Molecular Systems Engineering

\section{Introduction}

Molecular modules are the fundamental building blocks for the molecular factories to which the NCCR Molecular Systems Engineering aspires. Critical to the functioning of such factories is control over the ordering of, and interactions between, the molecular modules and compartments that comprise each larger assembly. Active or functionalized surfaces are a key stage on which working platforms may be constructed. In this article, we overview different means by which such platforms are being assembled and applied within five groups in the NCCR Molecular Systems Engineering. We present approaches to the difficult challenge of interfacing hard and soft domains, ways of tethering (ultimately active) compartments to surfaces, strategies for functionalizing surfaces with natural products, and the development of biosensors based on 'hard' silicon nanowires. The design strategies discussed below demonstrate our varied approaches to a single goal of producing functionalized surfaces which have the potential (proven or future) to be used in molecular systems for a wide range of sensing and chemical

${ }^{*}$ Correspondence: Prof. C. E. Housecroft ${ }^{a}$ E-mail: catherine.housecroft@unibas.ch aDepartment of Chemistry, University of Basel Spitalstrasse 51, $\mathrm{CH}-4056$ Basel

bDepartment of Chemistry, University of Basel Klingelbergstrasse 80, CH-4056 Basel

'Department of Chemistry, University of Zurich

Winterthurerstrasse 190, CH-8057 Zurich

dDepartment of Physics, University of Basel

Klingelbergstrasse 82, $\mathrm{CH}-4056$ Basel

eSwiss Nanoscience Institute, University of Basel

Klingelbergstrasse 82, $\mathrm{CH}-4056$ Basel reactivities. These different strategies still have to be adapted and extended to allow interfacing of different type of surfaces, specific interactions at a molecular level, and possible exchange of signals/cargoes between them. Such challenges provide a complex scenario of requirements that will ultimately be addressed in an integrated overall strategy. Optimization of the present approaches from each research group will be directed both to extend the types of functional surfaces and their resulting properties, and to cope with different specificities resulting from interfacing of different functional surfaces.

\section{'Surfaces-as-Ligands': A Platform Technology for Softening Hard Surfaces \\ Catherine E. Housecroft, Alexandra Wiesler, Angelo Lanzilotto, and Edwin C. Constable}

Our focus lies in the hierarchical assembly of multifunctional interfaces which combine biological complexity and organization with addressable material substrates. Three themes serve to exemplify our approach: the assembly of lightharvesting conjugates with energy-transfer properties, communication between energy-transfer systems for incorporation into first-generation molecular factories, and the functionalization of surfaces to template highly-organized arrays of artificial compartments for molecular factories.

The assembly of multifunctional interfaces requires an adaptive molecular assembly process and a precisely coded anchoring to and organization of the molecular components at the interface. Typically, the 'interface' is a hard surface such as a transparent conducting oxide glass electrode (fluorine-doped tin oxide, FTO, or indium-doped tin oxide, ITO). In the context of dye-sensitized solar cells (DSCs), we have pioneered a stepwise process for the assembly of surface-anchored molecular dyes. The surface comprises FTOsupported sintered nanoparticles of $\mathrm{TiO}_{2}{ }^{[1]}$ which provide an extremely large surface area while permitting the DSC device to retain a small size.

Development of our 'surfaces-as-ligands, surfaces-as-complexes' approach has enabled the fast screening of dyes in DSCs and the complementary routes shown in Schemes 1 and 2 have been optimized. ${ }^{[2-4]}$ The approach in Scheme 1 has primarily been used for the assembly of surface-bound heteroleptic copper(I) complexes which are unstable in solution:

$$
2\left[\mathrm{Cu}(\mathrm{L})\left(\mathrm{L}^{\prime}\right)\right]^{+} \rightleftharpoons\left[\mathrm{Cu}(\mathrm{L})_{2}\right]^{+}+\left[\mathrm{Cu}\left(\mathrm{L}^{\prime}\right)_{2}\right]^{+}
$$

The surface-bound sensitizers are assembled in a hierarchical fashion starting with functionalization of the surface with a carboxylic acid or phosphonic acidfunctionalized bis(diimine) ligand, $\mathrm{L}$ followed by treatment in a second dyebath with a labile homoleptic complex $\left[\mathrm{M}\left(\mathrm{L}_{\text {capping }}\right)_{2}\right]^{n+}$, leading to the formation of the surface bound $\left[\mathrm{M}\left(\mathrm{L}_{\text {anchor }}\right)\left(\mathrm{L}_{\text {capping }}\right)\right]^{n+}$. For complexes which are less labile, the method in Scheme 2 is applied. Here, assembly of the surface-bound system occurs in a stepwise manner, starting with the anchor, followed by treatment with a simple metal salt, and finally the capping ligand. The beauty of this approach is that 
it is a versatile means of softening hard surfaces; the capping domain can range from a simple organic ligand to a ligandfunctionalized nano-compartment, giving access to elegant platforms for molecular factories which will be assembled within the framework of the NCCR-MSE. As Scheme 2 illustrates, in practical terms, the strategy consists of a series of simple solution-dipping steps, which must be optimized for each system. The introduction of co-adsorbants allows control of the spatial arrangement, separation and intermolecular interactions between adjacent species on the surface. ${ }^{[5,6]}$

The conversion of a hard metal oxide surface into a soft-functionalized domain ('surfaces-as-ligands') which can be sequentially modified with a series of hierarchical building blocks, has proven potential for assembling arrays that are robust, precisely defined by a simple algorithm and temporally persistent. The approach has advantages over assembly principles predicated upon the anchoring of preformed functionalities. For example, light-harvesting domains based upon $\left\{\mathrm{Ru}(\mathrm{tpy})_{2}\right\}^{2+},\left\{\mathrm{Ru}(\mathrm{bpy})_{3}\right\}^{2+}$ or $\left\{\mathrm{Ru}(\mathrm{bpy})_{2} \mathrm{X}_{2}\right\}$ (tpy $=2,2^{\prime}: 6^{\prime}, 2^{\prime \prime}$-terpyridine, bpy $=2,2^{\prime}$-bipyridine) are frequently used in DSCs and are synthesized in their entirety prior to surface functionalization. We recently extended this approach to the assembly of a ruthenium porphyrin-terpyridine conjugate, as proof-of-concept for the incorporation of bioinspired structural motifs into hierarchical structures (Fig. 1). ${ }^{[7]}$ In this case, significant synthetic effort was required to prepare the conjugate. Attachment to a $\mathrm{TiO}_{2}$ surface was easily achieved through the use of phosphonate anchoring-domains, but although the conjugate showed the enhanced light-absorption, the desired electron-injection which was the goal of the assembly, proved inefficient and, in collaboration with the group of Oliver Wenger (University of Basel), we have shown that triplet-triplet energy transfer processes are likely responsible for this poor performance. ${ }^{[7]}$

As shown in the preceding discussion, we have demonstrated the potential of the 'surface-as-ligands' approach for the incorporation of bio-motifs. We are currently extending the approach to functionalization by nano-compartments such as polymersome vesicles. We have previously shown that introducing a tpy-functionalized phospholipid at low concentration into solutions containing phospholipid vesicles results, after the addition of $\mathrm{Fe}^{2+}$, in the formation of aggregates of vesicle. ${ }^{[8]}$ This assembly process depends upon penetration of the phospholipid moiety attached to the tpy domain through the vesicle walls. An alternative strategy is the direct functionalization of the vesicle compartments

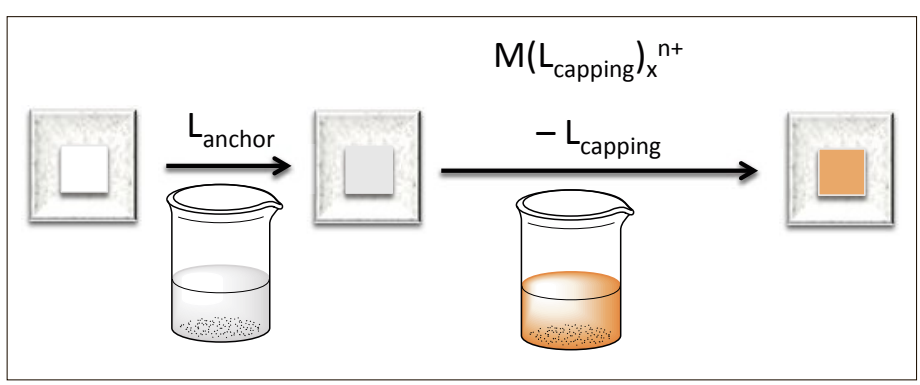

Scheme 1. Surfacefunctionalization by two-step complex assembly involving ligands exchange in the second step.

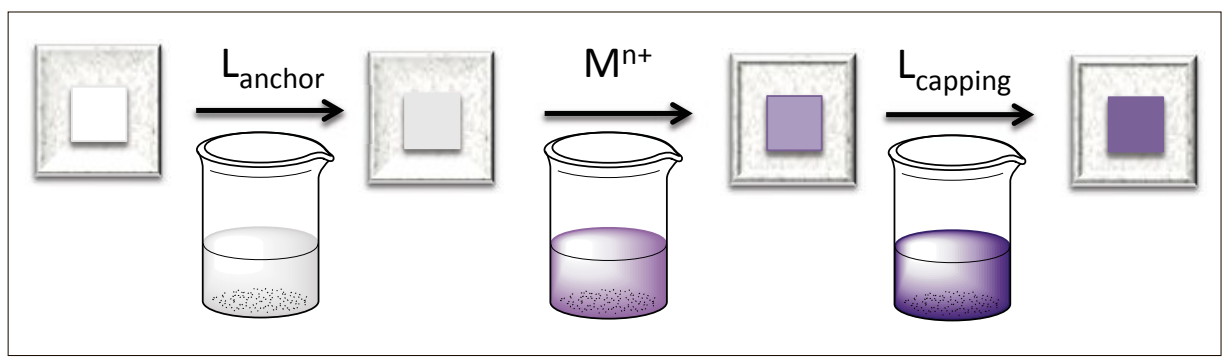

Scheme 2. Surface-functionalization by three-step complex assembly.

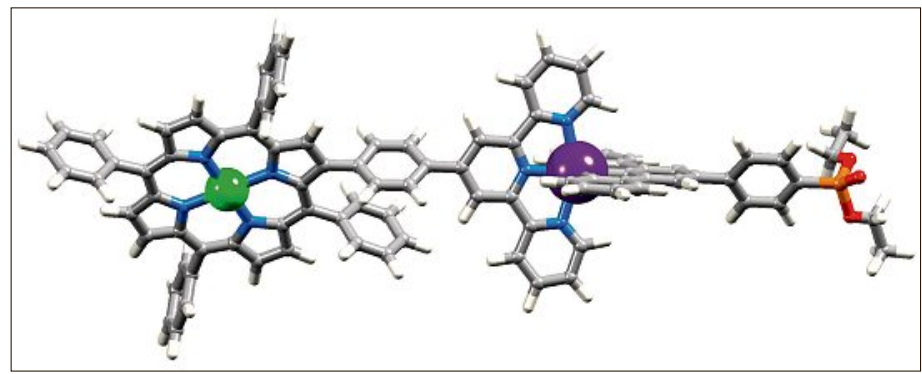

Fig. 1. Ruthenium porphyrin-terpyridine conjugate with phosphonate anchoring domain (right) suited for functionalization of $\mathrm{TiO}_{2}$ which can be achieved in collaboration with the Palivan group in Basel, providing capping building blocks for the final step in the surface-functionalization. Before such capping units can be introduced, controlled patterning of the surface must be achieved. The phosphonic-acid functionalized tpy ligand, 1, shown in Fig. 2a, binds to FTO/ $\mathrm{TiO}_{2}$. However, the addition of $\mathrm{FeCl}_{2}$ leads to the formation of $\left\{\mathrm{Fe}(\mathrm{tpy})_{2}\right\}^{2+}$ domains as confirmed by an immediate change in color from colorless to purple as the tpyfunctionalized $\mathrm{FTO} / \mathrm{TiO}_{2}$ glass slides are immersed in aqueous $\mathrm{FeCl}_{2}$. Solid-state absorption spectra of the functionalized surfaces show a characteristic metal-toligand charge transfer (MLCT) band at $573 \mathrm{~nm}$. These results indicate that, on the nanoparticulate surface, the orientations of the adsorbed ligand lead to capture of $\mathrm{Fe}^{2+}$ by two adjacent ligands giving anchored $\left[\mathrm{Fe}(\mathbf{1})_{2}\right]^{2+}$. Fig. 2b shows an atomic force microscopy (AFM) image of the clean $\mathrm{TiO}_{2}$ surface, confirming its roughness. In comparison with the height scale-bar of $0-48.4 \mathrm{~nm}$, the dimensions of the mod-

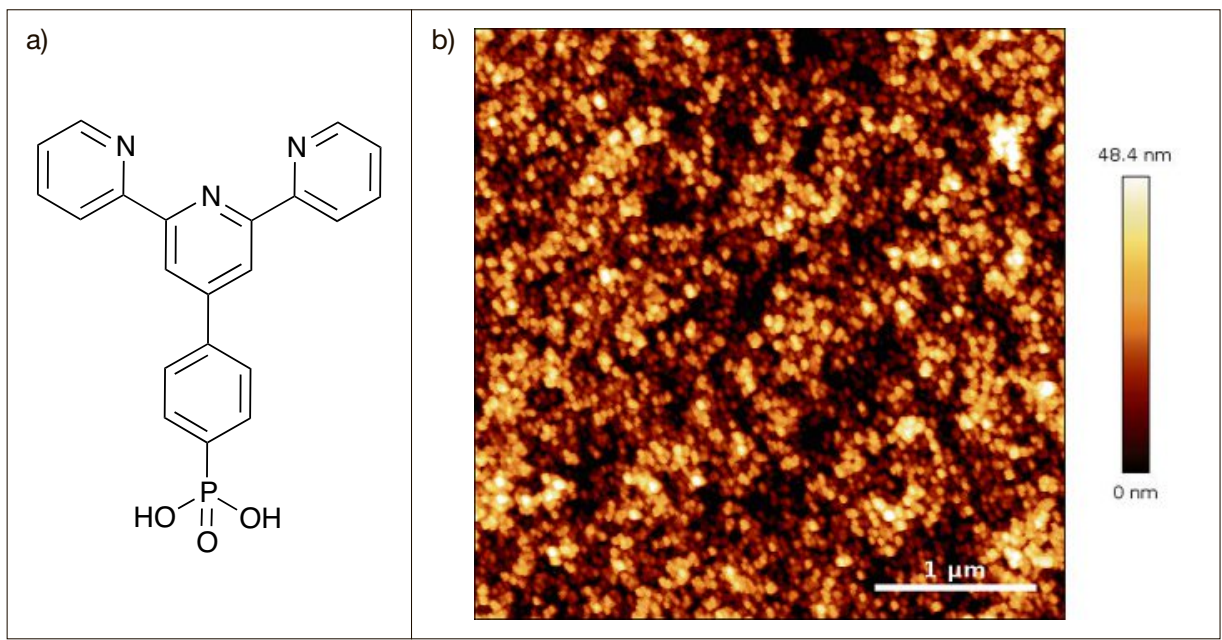

Fig. 2. (a) Structure of anchoring ligand 1. (b) AFM image of a clean $\mathrm{TiO}_{2}$ surface to assess the size of surface pores. 
eled $\left[\mathrm{Fe}(\mathbf{1})_{2}\right]^{2+}$ complex are $c a .2 .4 \times 1.1$ $\mathrm{nm}$, confirming that ligands $\mathbf{1}$ are small enough to be adsorbed within the surface pores so that they face one another across the cavities. The high stability constant of the $\left[\mathrm{Fe}(\mathbf{1})_{2}\right]^{2+}$ complex $\left(\log \beta_{2} \sim 20\right)$ renders its formation irreversible, and therefore we have introduced coadsorbants to disperse the adsorbed ligands $\mathbf{1}$ over the surface in order to preserve the $\left\{\left(\mathrm{L}_{\text {anchor }}\right) \mathrm{Fe}\right\}$ domain as an active species required to trap a capping ligand or nano-compartment. This strategy is successful, and we are currently optimizing the aqueous conditions using a range of buffers that are tolerated by both the iron(II) (or other metal ion) complexes and polymersome vesicles. Stability tests have been carried out using anchored $\left[\mathrm{Fe}(\mathbf{1})_{2}\right]^{2+}$ complexes in which a second equivalent of $\mathbf{1}$ acts as a model capping domain. The complex is assembled on an FTO/TiO, surface according to Scheme 2, and then the functionalized surface is immersed in an aqueous solution for 72 hours before being dried. Fig. 3 shows the MLCT band in the solid-state absorption spectra of the surface bound $\left[\mathrm{Fe}(\mathbf{1})_{2}\right]^{2+}$ before and after exposure to buffer solutions. The MLCT band in the absorption spectrum of surface-bound $\left[\mathrm{Fe}(\mathbf{1})_{2}\right]^{2+}$ significantly decreased following exposure to PBS buffer (Fig. 3), indicating that most of the complex has been desorbed from the surface. In comparison, the MLCT bands in the absorption spectra of the other surfaces retain their intensities after exposure to HEPES, TES, water or saline solution. This indicates a very good stability of the modified surfaces in these buffers.

In concluding this section on hierarchical assembly of multifunctional interfaces, we draw attention to the versatility of the 'surfaces-as-ligands' strategy for the softening of hard surfaces by the programmed incorporation of bio-inspired functionality. In the context of assembling molecular factories, overcoming the hard-soft interface is a significant challenge. Our approach, which relies upon designing suitable anchoring domains coupled with metal recognition and subsequent capping with a range of domains, is extremely versatile, and should provide a suitable technology platform for the assembly of complex systems on surfaces.

\section{Functional Synthetic Membranes by Insertion of Biomolecules Viktoria Mikhalevich and Wolfgang Meier}

Cell membranes are of crucial importance for life due to their functions in cell protection, organization and transport of molecules. These biomembranes, which are either cell boundaries or organelle

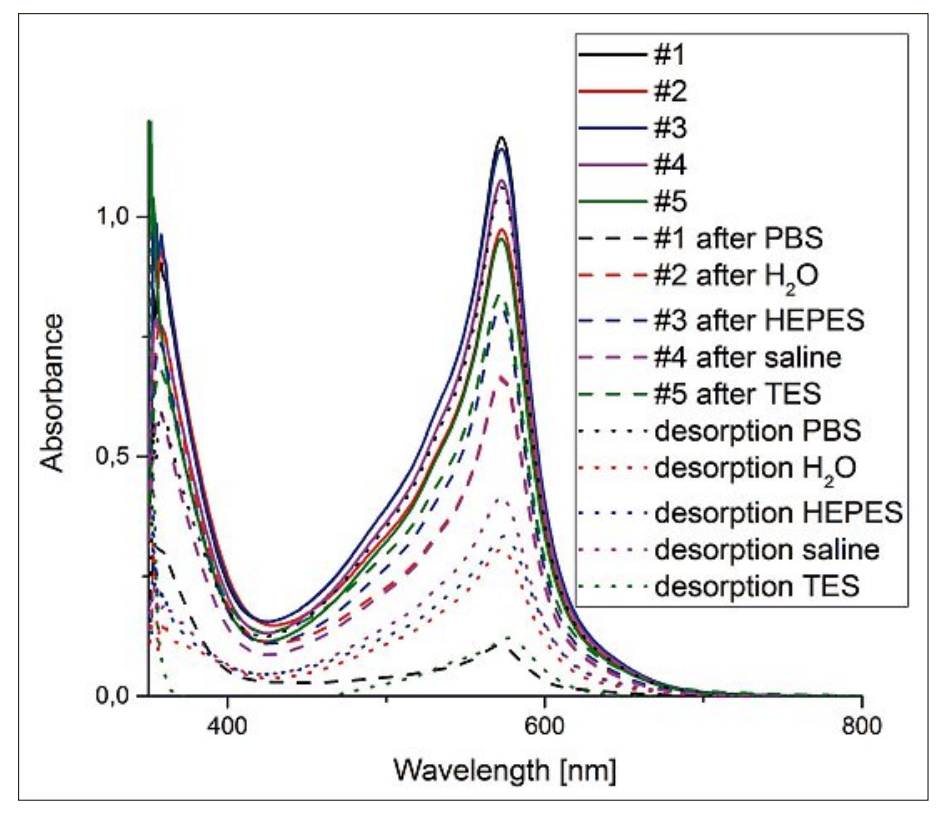

Fig. 3. Solid-state absorption spectra of surface bound $\left[\mathrm{Fe}(1)_{2}\right]^{2+}$ before and after exposure to aqueous or buffered aqueous solutions. PBS = phosphate-buffered saline, HEPES $=$ 2-(4-(2-hydroxyethyl) piperazin-1-yl)ethanesulfonic acid, TES = $\mathrm{N}$-tris(hydroxymethyl) methyl-2-aminoethanesulfonic acid.

boundaries, consist of lipid bilayers with a variety of incorporated biomolecules, such as membrane proteins. ${ }^{[9]}$ Membrane proteins play a central role in basically all physiological processes, and therefore constitute about $60 \%$ of approved drug targets. ${ }^{[10]}$ Therefore, it is essential to study biomembranes properties and investigate how to use a biomimetic strategy to develop synthetic membranes with improved stability than lipid bilayers and preserved multifunctionality. An elegant and straightforward approach to mimic biomembranes is to use model planar membranes, the most promising in terms of stability, being solid-supported membranes (the membrane is physically or chemically attached to a solid substrate, such as glass or silica). Lipid bilayers on solid substrates, often used as cell-surface models ${ }^{[11]}$ have unfortunately various drawbacks, such as low stability, presence of uncontrolled defects of the membrane, and a difficult chemical modification if required. In addition, the low bilayer thickness $(3-5 \mathrm{~nm})$ induces a higher interaction of the inserted membrane proteins with the solid support, which might affect the protein structure or functionality. These drawbacks are overcome by using polymer membranes, in particular membranes based on amphiphilic copolymers with the advantages of improved mechanical stability, tunable thickness (5-40 nm), and easier chemical modification. ${ }^{[12]}$ Due to the increased membrane thickness, inserted membrane proteins have lower interactions with the support, and therefore are able to behave as in a natural environment.[13] To further mimic cell-membranes, biomolecules can be either attached on the surface or inserted inside the synthetic membrane (Fig. 4). ${ }^{[14]}$

The insertion (reconstitution) of membrane proteins/biopores inside synthetic membranes is a challenging process that requires a complex scenario of conditions in order to preserve the structure and functionality of the biomolecule in a completely synthetic environment. Our group introduced the first examples of biopores and membrane proteins inserted in solidsupported membrane by adapting the molecular properties of different amphiphilic block copolymers, such to self-assemble in membranes with flexibility and fluidity similar with those of biomembranes. Both diblock and triblock copolymers, such as poly(dimethylsiloxane)-block-poly(2methyloxazoline) (PDMS-PMOXA) and (PMOXA-PDMS-PMOXA), known to be biocompatible have been synthesized with appropriate hydrophobic-to-hydrophilic ratio and formed compartments with membranes with the necessary fluidity ${ }^{[15]}$ to allow insertion of membrane proteins. ${ }^{[16]}$ Interestingly, the high hydrophilic mismatch between the size of the membrane proteins and the thickness of the synthetic membrane has been overcome by the membrane flexibility, which allowed a

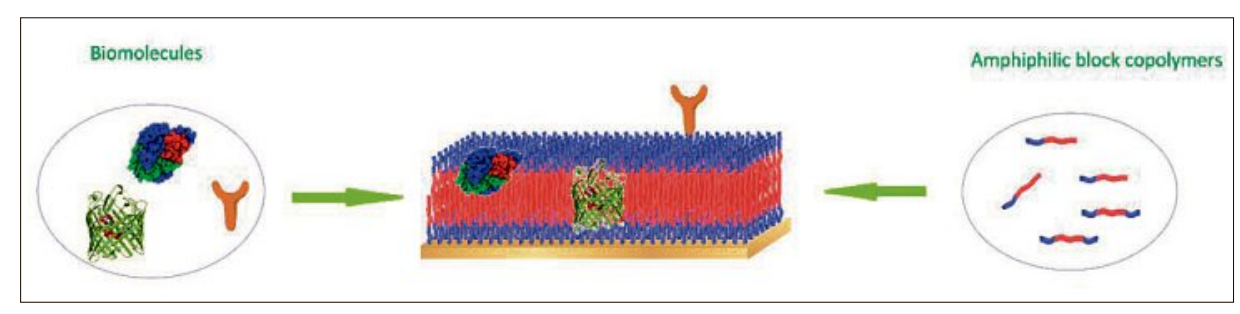

Fig. 4. Schematic formation of a protein-polymer solid-supported planar membrane. 
functional insertion of the biomolecules as proved for various biopores and membrane proteins. ${ }^{[16,17]}$

We extended the insertion of membrane proteins in planar solid-supported membranes in collaboration with the group of C. Palivan (University of Basel). The first example of a successful insertion of a biopore in a completely artificial tethered, solid-supported membrane (TSSBM) of amphiphilic poly(butadiene)-blockpoly(ethylene oxide) (PB-PEO) copolymers has been obtained for the model bacterial membrane polypeptide $\alpha$-haemolysin, $\alpha \mathrm{HL}$ (Fig. 5A). ${ }^{[18]}$ TSSBM is bound to the surface via 'tether molecules', which provide both a higher membrane stability, and longer membrane-support distance serving to prevent interactions between the inserted membrane protein/biopore and the solid support. TSSBM prepared by the Langmuir-Blodgett technique, were directly immersed in $\alpha \mathrm{HL}$ solution, and then an electric current was applied to destabilize the membrane and favor the polypeptide insertion. In nature, $\alpha H L$ forms heptameric transmembrane nanopores, which allow the passive diffusion of solutes, such as ions across the membrane. ${ }^{19]}$ Therefore, the incorporation of $\alpha \mathrm{HL}$ in the synthetic solid-supported membrane has been directly observed in a qualitative and quantitative manner, based on conductance changes (Fig. 5B). The transport of ions through $\alpha \mathrm{HL}$, and their accumulation in the inner small domain of the copolymer membrane were modelled by the Donnan model.[18]

This membrane protein insertion method, in which electric current is applied to destabilize the synthetic membrane and favor insertion can be extended to other water-soluble biomolecules thus opening the possibility for simultaneous insertion of different biopores/membrane proteins such as to induce multifunctionality similar to membrane complexes in biomembranes.

A different scenario of conditions is necessary when hydrophobic membrane proteins are intended to be inserted into solid-supported polymer membranes. The first successful example of a hydrophobic model membrane protein inserted in a solid-supported membrane is the potassium channel of the bacterium Mesorhizobium loti, MloK1.[20] The protein was first stabilized in detergent, and then added to the solid supported membrane kept in aqueous solution. The solubilization of the membrane protein was followed by a slow removal of the detergent with biobeads. The lack of the stabilizing detergent represented the driving force for the protein insertion into the hydrophobic part of the solid-supported PDMS-PMOXA bilayer (Fig. 5C). The increase in conductance of
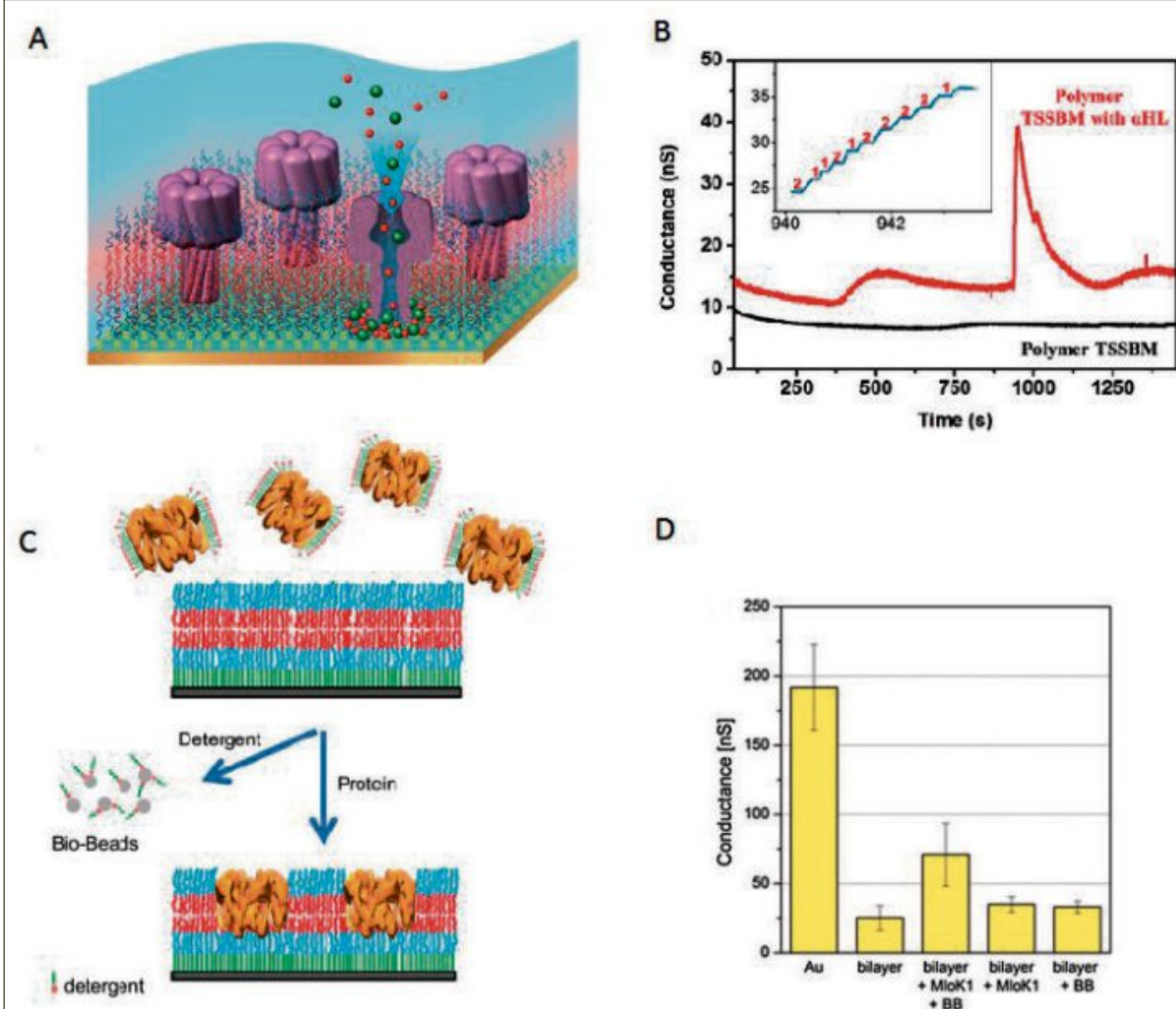

D

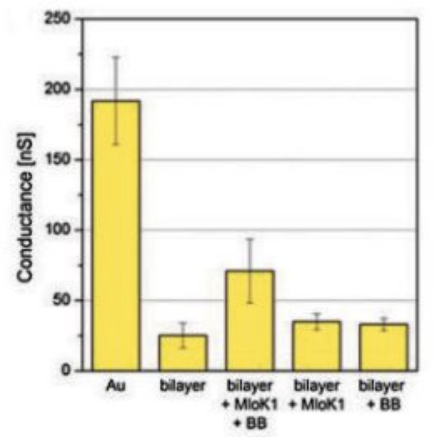

Fig. 5. A) Schematic representation of the tethered solid-supported PB- $b$-PEO bilayer membrane and the inserted $\alpha \mathrm{HL}$. B) Time course for conductance across the membrane before (black curve) and after (red curve) addition of $\alpha \mathrm{HL}$, at a voltage of $40 \mathrm{mV}$. C) Schematic representation of membrane protein insertion into solid-supported polymer membrane with usage of bio beads. D) Conductance measured at a constant applied voltage of $40 \mathrm{mV}$ (Au - gold substrate, BB - bio beads) ${ }_{[}^{[10,18]}$

the protein-incorporated polymer membrane indicated a successful functional insertion of MloK1 (Fig. 5D). [20]

Together these insertion methods developed for hydrophilic and hydrophobic biopores/membrane proteins represent a step forward in development of multifunctional protein-polymer membranes and are suitable for engineering functional surfaces on solid substrates of unrestricted size, which will favor interfacing with different modules required for the design of molecular factories.

As in various biomembranes the lipids form nanodomains with different thickness and fluidity, which can trigger the distribution of membrane proteins, ${ }^{[21]}$ it is of an essential interest to study how to mimic such membranes containing different nanodomains. Our group introduced an elegant manner to generate hybrid membranes by transferring lipid-polymer mixtures via the Langmuir-Blodgett technique. Our interest is to combine both phospholipid and synthetic polymer membrane properties and advantages, providing a more complex environment to investigate the behavior and interactions of biomolecules. ${ }^{[22]} \mathrm{We}$ transferred PDMS- $b$-PMOXA copolymers with different lengths and hydrophobic to hydrophilic ratio and two different lipids on solid support, and investigated the distribution of the potassium channel MloK1 Nanodomain formation was dependent on the length of the polymer, the character of the lipid and on the ratio of polymer and lipid (Fig. 6A, B). The lipids dipalmitoylphosphatidylcholine (DPPC) and 1,2-dioleoyl-sn-glycero-3-phosphocholine (DOPC) form different type of domains: DPPC forms flower-like shaped domains, whilst DOPC forms small spherical domains due to their differences in the chemical and physical properties. Surprisingly, the protein was distributed in the polymer phase in the case of DPPC (shown green on the CLSM micrographs, Fig. 6C, D) and not in the lipid phase as might have been expected. In contrast, the protein was distributed in the lipid phase in the case of DOPC. Therefore, by changing the composition and ratios of polymer-lipid mixtures, the properties of the membrane trigger the distribution of the protein in specific nanodomains.

We plan to extend such hybrid planar solid-supported membranes by using mixtures of peptides and polymers. Study of binary monolayers of PMOXA-PDMSPMOXA triblock copolymers and alamethicin, a small amphiphilic antimicrobial peptide, indicated that the larger the polymer, the higher is its flexibility and ability to adopt conformations allowing host peptides in the membrane. ${ }^{[23]}$ Both lipid-poly- inside the resulting hybrid membranes. ${ }^{[22]}$ 

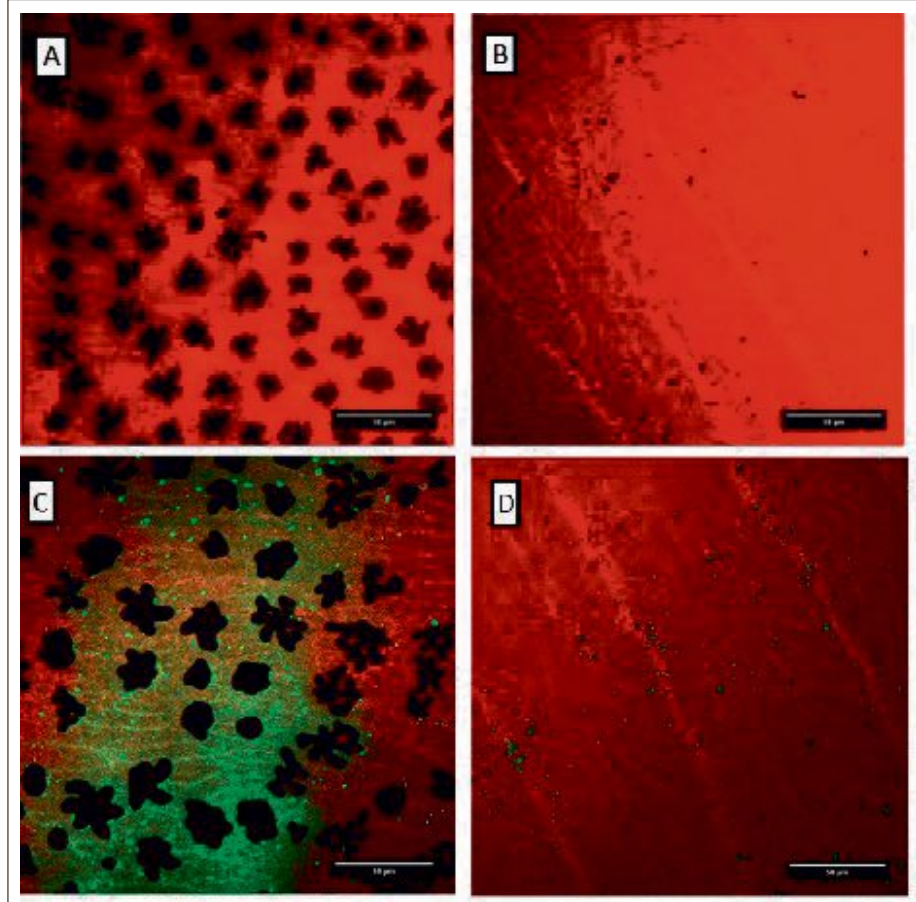

Fig. 6. CLSM micrographs of A) $\mathrm{PDMS}_{65}$ $b$-PMOXA $(x$ $=0.25)-D P P C$, C)PDMS $-b-$ $\mathrm{PMOXA}_{12}\left(x_{\text {polymer }}\right.$ 0.25)-DOPC, CLSM micrographs showing the protein distribution in films consisting of mixtures of PDMS $_{65}-b-$ PMOXA $_{12}$ and C) DPPC $\left(x_{\mathrm{DPPC}}=\right.$ $0.75)$, D) DOPC $\left(x_{\mathrm{DPPC}}\right.$ $=0.25)$.

mer and peptide-polymer hybrid membranes are intended to act as hybrid templates with domains for specific interaction with biomolecules/active compounds in order to pattern complex functional surfaces necessary in the design of molecular factories. The presence of various domains with different properties and functionality are required when various modules have to be implemented on a surface and generate a complex reply.

\section{'Active Surfaces' by Attachment of Enzymes on Planar Membranes or Immobilization of Nanoreactors on Solid Supports Xiaoyan Zhang and Cornelia G. Palivan}

Design of hybrid materials with specific properties and functionality at the interface with their environment has high potential for applications in domains rang- ing from catalysis to medical and environmental sciences. A particularly appealing strategy is to design 'active surfaces' by combining active compounds (biomolecules, mimics) with synthetic planar membranes attached on solid support, such to profit from the intrinsic activity of the biomolecules and the stability by the synthetic membranes. ${ }^{[24]}$ There are two effective ways to immobilize biomolecules on solid supports: i) cover the support with soft layers (e.g. lipid or polymers) to embed the biomolecules and avoid denaturation on contact with the support ${ }^{[25,26]}$ and ii) encapsulate the biomolecules in lipid or polymer compartments that are immobilized on the support. [27] Synthetic membranes are the preferred template when combining with biomolecules for technologic applications because of the higher stability in time and robustness compared to lipid bilayers, in addition to the possibility in fine-tuning their properties (flexibility, architectures and responsiveness). ${ }^{[28]}$
Asymmetric ABC triblock copolymers represent ideal candidates for performing a directional membrane protein insertion/ attachment or to generate membranes with a different specificity at each surface. The asymmetry of a polymer membrane plays a key role in favoring the functionality of active surface with the desired orientation at the external membrane interface, whilst the lower polymer block serves to bind to the solid support. Thin films of nonamphiphilic ABC triblock copolymers have been reported to interact with bovine serum albumin, ${ }^{[29]}$ whilst our group introduced a more advanced approach for immobilization of enzymes on solid supports by using solidsupported polymer monolayers based on asymmetric amphiphilic copolymers (Fig. 7A). ${ }^{[25]}$ We were first interested to have an improved insight on: i) how ABC copolymers are organized under compression at the air-water interface, ii) what is the orientation of the hydrophilic blocks at the air-water interface, iii) what are the structural properties favoring film formation and enzyme adsorption, and iv) whether the activity of the enzyme is preserved when attached to the synthetic monolayer. A group of six poly(ethylene glycol)-block$\operatorname{poly}(\gamma$-methyl- $\varepsilon$-caprolactone $)$-blockpoly[(2-dimethylamino) ethyl methacrylate] $\left(\mathrm{PEG}_{45}-b\right.$-PMCL $-b$-PDMAEMA $)$ copolymers ${ }^{[30]}$ was investigated in terms of their behavior at the air-water interface, formation of films on a solid support, and ability to adsorb a model enzyme (i.e. laccase).[25] The Langmuir-Blodgett (LB) transfer technique was selected for the solid-supported membrane formation because it allows the density of the resulting monolayer to be controlled and has a higher reproducibility compared to other 'grafting to' methods (i.e. direct polymer adsorption from the solution, spreading, and fusion of vesicles). ${ }^{[28,31]}$ The properties of the films varied, depending on the surface pressure of transfer, ABC molecular properties (hydrophilic/hydrophobic blocks length and active groups), and $\mathrm{pH}$. At the air-water
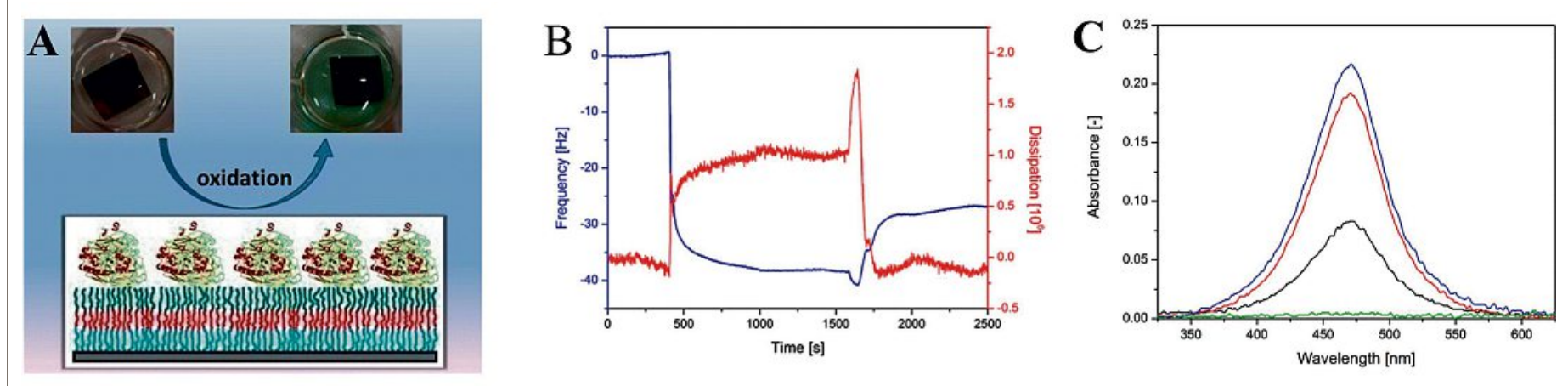

Fig. 7. A) Scheme of 'active surfaces' formed by immobilization of enzymes on solid-supported polymer membranes and the photo of active surfaces before and after enzyme reaction. $\left.{ }^{[25]} B\right)$ Representative QCM-D data for laccase adsorption on ABC triblock copolymer film. C) Spectroscopic evaluation of laccase activity based on formation of a DMP oxidation product $(\lambda=470 \mathrm{~nm}$ ) for free laccase (black), polymer monolayer with laccase adsorbed by immersion (red), and transferred mixed ABC-laccase film (blue); a polymer monolayer without laccase (green). 
interface, films were oriented with the PEG domain in the water subphase and the PDMAEMA domain facing toward air. Laccase was successfully immobilized on the membrane either via immersion of solid-supported polymer films in enzyme solutions, or transfer of mixed ABC-enzyme films on silica slides (Fig. 7B). Functional surfaces based on solid-supported laccasepolymer films were both stable and active (Fig. 7C). This approach to generate active surfaces is straightforward and biofriendly allowing further extension of the functionality by simply changing the type of enzyme.

A step further in obtaining more robust polymer membranes for combination with enzymes is to generate bilayers/multilayers of asymmetric triblock copolymers, and combine them with active compounds, such as enzymes or mimics. In this context, we performed successive deposition/transfer of two layers of $\mathrm{PEG}_{45}-b$-PMCL $\mathrm{PM1}_{101}-b$ PDMAEMA $_{27}$. The first layer of the triblock copolymer was transferred on solid support by emersion of silica slides from the water subphase (up movement), whilst the second layer was transferred either by emersion followed by immersion transfer (resulting in an 'up-down' bilayer) or by two consecutive emersion transfers (resulting in an 'up-up' bilayer). Preliminary results indicate that the molecular properties of these membranes (bilayer thickness, wettability, film topography/roughness) influence both the resulting surface properties and the enzyme adsorption ability (Fig. 8).

Therefore, depending on the desired application it is possible to trigger the surface properties and the resulting functionality mediated by the adsorbed biomolecules, which opens new perspectives for development of locally controlled multifunctional surfaces.

Another elegant way to combine active compounds (enzymes, proteins, mimics) with synthetic templates is based on immobilization on solid support of nanoreactors. Nanoreactors are reaction spaces at the nanoscale resulting from encapsulation/insertion of active compounds inside compartments with sizes in the nanometer range (e.g. polymersomes). ${ }^{[32]}$ In collaboration with the group of W. Meier (University of Basel) we developed a versatile and efficient method for compartment immobilization via an aldehyde-amino reaction: aldehyde groups exposed at the compartment external surface react with amino groups of chemically modified glass surfaces. ${ }^{[27]}$ This immobilization method enables stable immobilization of compartments on solid supports. In addition, the mild conditions of enzymes/proteins encapsulation/insertion and immobilization of the nanoreactors do not affect the activ-

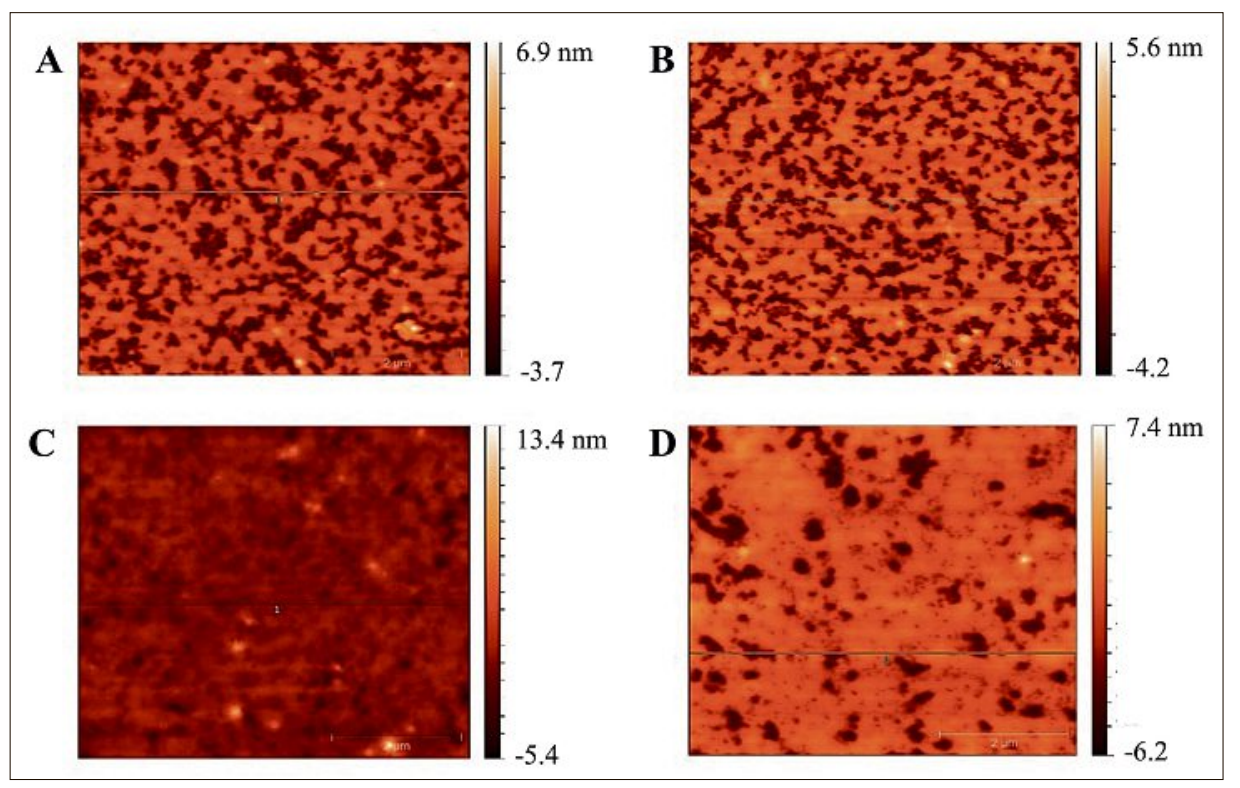

Fig. 8. AFM images of bilayers of $A_{45} B_{101} C_{27}$ triblock copolymer with different deposition types: up-down fresh sample (a), up-down one week old sample (b), up-up fresh sample (c), and up-up one week old sample (d); scale bars are $2 \mu \mathrm{m}$.

ity of the encapsulated biomolecules, and therefore the functionality of the resulting active surfaces. The rapid exchange of molecules with the environment, as an essential parameter of nanoreactor efficacy, is supported by insertion of channel porins in the wall of compartments: substrates and products freely diffuse through, whilst the encapsulated enzymes cannot escape from the inner cavity having a higher size than the diameter of the channel. ${ }^{[32]} \mathrm{A}$ first example of such active surfaces based on immobilization of nanoreactors served for controlled production and release of antibiotics for long periods of time. ${ }^{[27,33]}$ The immobilization method preserved the vesicular structure of the nanoreactors, and did not influence the enzymatic activity of the encapsulated catalyst for up to 7 days. Such self-defending surfaces allow a control of drug production at a specific rate for long periods of time by adding the required amounts of substrate to the outer medium.

A step forward in gaining specificity of such active surfaces, as an essential requirement for development of molecular factories in which such surfaces will serve for interfacing different complex modules, and generating a specific reply (production of a required compound, detection of a specific molecule, signaling, etc.) is now under study in our group. We were successful to introduce polymer compartments with selective permeability by inserting specific membrane proteins allowing a controlled diffusion through the synthetic membrane, and immobilized them on solid support to engineer functional surfaces with the desired functionality. ${ }^{[34]}$ In this respect, we immobilized protein-polymer nanoreactors for sensitive detection of sugar alcohols by simultaneously encapsulating spe- cific enzymes inside polymersome cavity and inserting membrane proteins for selective diffusion of sugar alcohols (Fig. 9A). Despite the artificial surroundings, and the thickness of the copolymer membrane, the functionality of $E$. coli glycerol facilitator $(\mathrm{GlpF})$ was preserved, allowing a selective diffusion of sugar alcohols to the inner cavity of the polymersome, where ribitol dehydrogenase (RDH) served as biosensing entity. Ribitol, selected as a model sugar alcohol, was quantitatively detected in situ by RDH in a concentration range of 1.5-9 mM. When immobilized on solidsupport, the nanoreactors preserved their architecture and activity, and served for selective detection of sugar alcohols with high sensitivity due to the rapid change in the fluorescence intensity of the surface in the presence of sugar alcohols (Fig. 9B,C,D). One of the main advantages of this technology to engineer surface-based bioanalytical sensors is the possibility of rapidly screening multiple recognition events either sequentially or simultaneously. Due to the flexible size of the glass slides that can be functionalized with immobilized nanoreactors with inserted GlpF, our active surfaces provide an ideal platform to be further developed in combination with 'lab on a chip' devices ${ }^{[35]}$ for translational applications.

There are various advantages of such 'active surfaces': i) high selectivity due to the membrane protein specificity, ii) longterm stability of the encapsulated enzymes because of the protection the compartment provides simultaneously with free conditions for the biomolecules to act in situ, and iii) controlled conditions for enzymatic reactions, which occur only in the confined cavity of nanoreactors. In addition, 

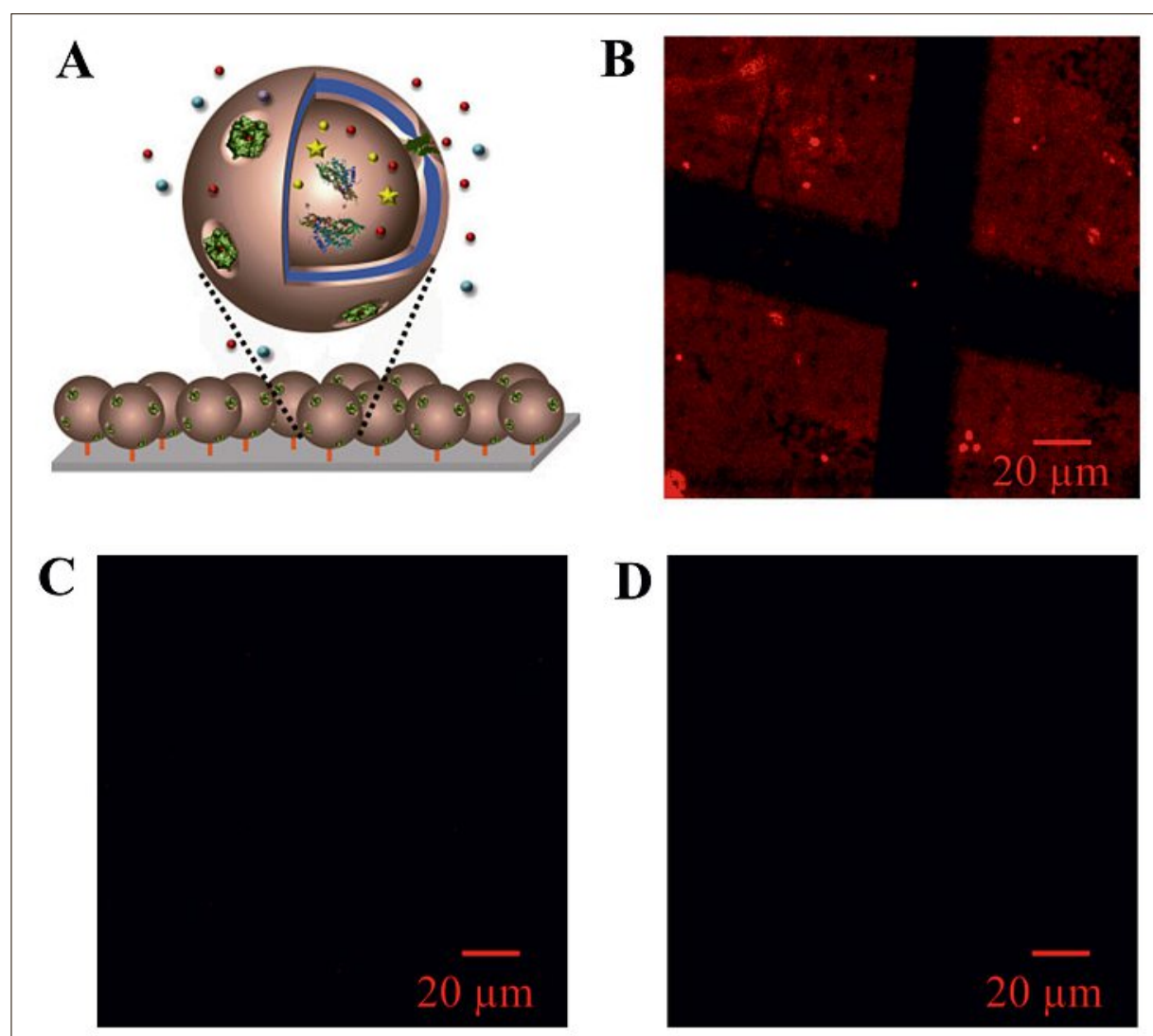

Fig. 9. A) Schematic representation of an 'active surface' serving for efficient detection of sugar alcohols based on immobilized protein-polymersome nanoreactors. The functionality of the nanoreactors is based on the insertion of membrane proteins $(\mathrm{GlpF})$ for selective passage through the synthetic membrane of sugar alcohols, and encapsulation of enzymes (RDH) for sensitive detection of sugar alcohols. CLSM micrographs of: B) the active surface with immobilized nanoreactors with inserted GlpF, C) the surface with nanoreactors without inserted GlpF, and D) the surface with nanoreactors based on copolymers, which cannot be immobilized on glass and were rinsed away by water.

the intrinsic properties of polymer compartments (stability, robustness), and of biological molecules (specificity, rapidity and selectivity) favor their use in the development of active surfaces with improved efficacy and desired multifunctionality. ${ }^{[32]}$ This concept opens a new area of nanomaterials that are safer and more efficient in order to match the complex scenario of requirements of molecular factories design.

\section{Natural Product-functionalized Surfaces \\ Ellen Piel, Mathieu Szponarski, and Karl Gademann}

Natural products, i.e. molecules obtained from natural sources, have influenced humans since ancient times. Nutrients provide the source for growth, vitamins allow people to live longer, dyes color our world, and scents influence our feelings. At the same time, humans are in contact with materials all day, from buildings to beds, from clothes to cell phones. We have developed a research program over the last decade that allowed for the combination of natural products with materials by generating functionalized surfaces. ${ }^{[36]}$
The resulting materials have the potential to serve as self-sterilizing implants, to prevent fouling in marine environments, and to help paralyzed people move again.

The idea of combining natural prodhumans since the beginning of mankind, as for example a recent study identified lipid-modified stone tools from around 3000 BC. ${ }^{[37]}$ With the advent of a detailed ucts with materials has been exploited by molecular understanding of both materials and natural products, driven by analytical and computational techniques, more sophisticated strategies were developed for surface functionalization. The prime challenge is the chemical compatibility of forming covalent, and preferably strong, bonds between the (modified) natural products and the material. Recognizing theories in the geosciences that natural iron chelators bind to mineral oxide surfaces, ${ }^{[38]}$ we began evaluating these so-called siderophores for their surface-binding properties (Fig. 10). In collaboration with the group of Marcus Textor at ETH, and then with Stefan Zürcher and Samuele Tosatti from the ETH spin-off SurfaceSolutionS, we developed catecholate-based surface anchors from the cyanobacterial siderophore anachelin. ${ }^{[39]}$ The first-generation compound was identical to a part of the siderophore and proved efficient in functionalizing metal oxides with polyethylene glycol (PEG) for antifouling applications. ${ }^{[40]}$ Evaluating the structural aspects for binding led to improved second-generation dopamine derivatives, ${ }^{[41]}$ but the recognition of the power of electron-withdrawing substituents culminated in the discovery of nitrodopamine as a simple yet powerful third-generation unit. ${ }^{[42]}$ Polymeric systems complement the molecular portfolio and display resistance to aquatic biofouling for over hundred days. ${ }^{[43]}$ Nitrodopamine has been used by many groups both in industry and in academia worldwide, as documented by dozens of publications ${ }^{[44]}$ and patents ${ }^{[45]}$ over the last five years, and is commercially available for various platforms. A further extension of the nitrodopamine linker is represented by the fourth-generation nitrocatechol, ${ }^{[46]}$ which allows for underwater bonding and debonding on demand. The catecholate can be adsorbed onto metal oxide surfaces in water, and the attached cargo can then be released on demand by an outside stimulus such as a light pulse.

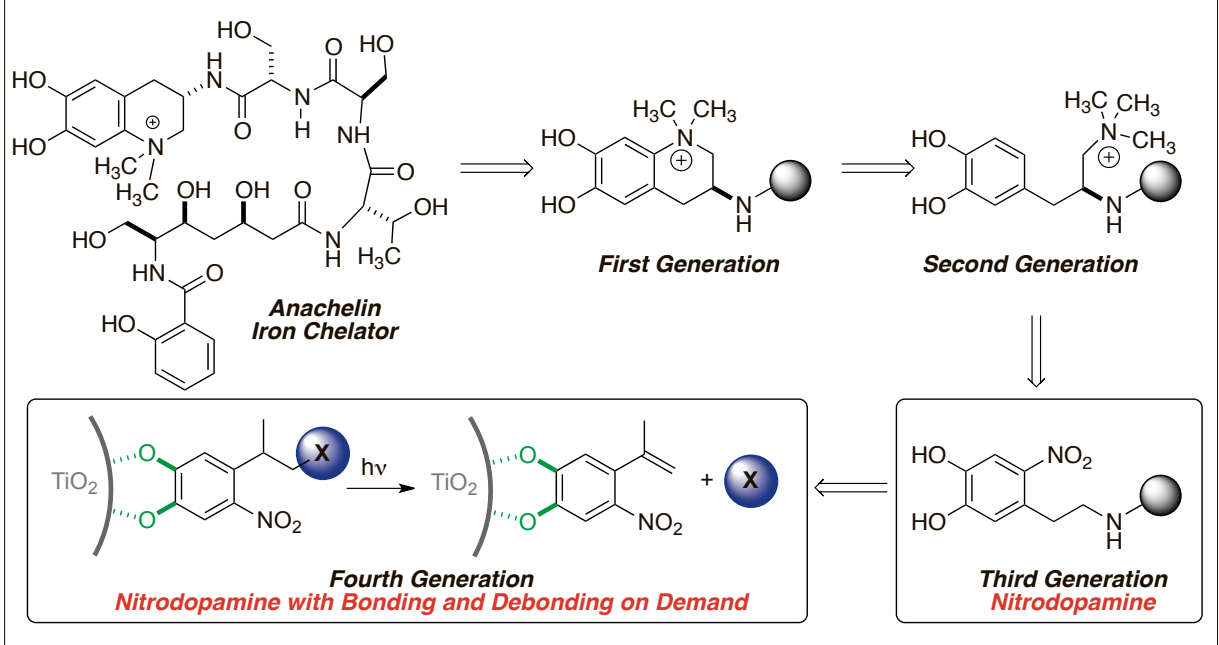

Fig. 10. Development of efficient surface modification anchors. 
All these systems have certain advantages over mussel-inspired catecholate coatings, which have also been very popular over the last years. ${ }^{[47]}$

After having identified a robust yet versatile surface platform, we have conjugated a variety of natural products to catechols. For example, we have prepared a hybrid of the antibiotic vancomycin, PEG linker, and a catecholate anchor (Fig. 11). ${ }^{[48]}$ Metal oxide surfaces such as titania can be modified with this antibiotic by an operationally simple dip-and-rinse coating from aqueous solution, and the resulting surfaces have been shown to display excellent antibiotic properties. ${ }^{[48]}$ A complementary approach to reduce the adhesion of bacteria is the chemical interference with quorum sensing, and to this goal, we have immobilized compounds that can interfere with the signaling system of bacteria. ${ }^{[49]}$ Biological assays demonstrated the validity and the power of this approach. ${ }^{[49]}$

Finally, one of the grand challenges in the field is the generation of surfaces that can stimulate neurite outgrowth. Such materials hold promise in neuroscience, as for example the reconstitution of injuries in the nerve system (nerve regeneration) could be obtained. While systems based on proteins have been evaluated for some time, we were first able to design and build neuritogenic materials by utilizing the bonding and debonding platform conjugated to a retinoid derivative. ${ }^{[50]}$ This compound could be immobilized on titania, and liberated by an external light pulse. A complementary system is based on the small molecules discovered in our program directed at identifying small molecules stimulating neurite outgrowth. ${ }^{[51]}$ Materials coated with compounds such as 2 (Fig. 11) were able to induce neurite outgrowth, and therefore constituted the first small molecule functionalized materials for nerve regeneration. This approach is complemented by other methods, such as the use of microtubule interfering agents, ${ }^{[52]}$ which have been developed independently.

In summary, we have developed a robust surface modification platform that is able to functionalize materials with a broad range of natural products, and thereby generating new matter with interesting properties with potential to self-sterilizing implants and nerve regeneration.

\section{ISFET Biosensing for Molecular Systems and Factories Monitoring Axel Fanget, Ralph L. Stoop, and Michel Calame}

Living cells use ions and biomolecules to maintain and regulate their activity in complex environments and to achieve

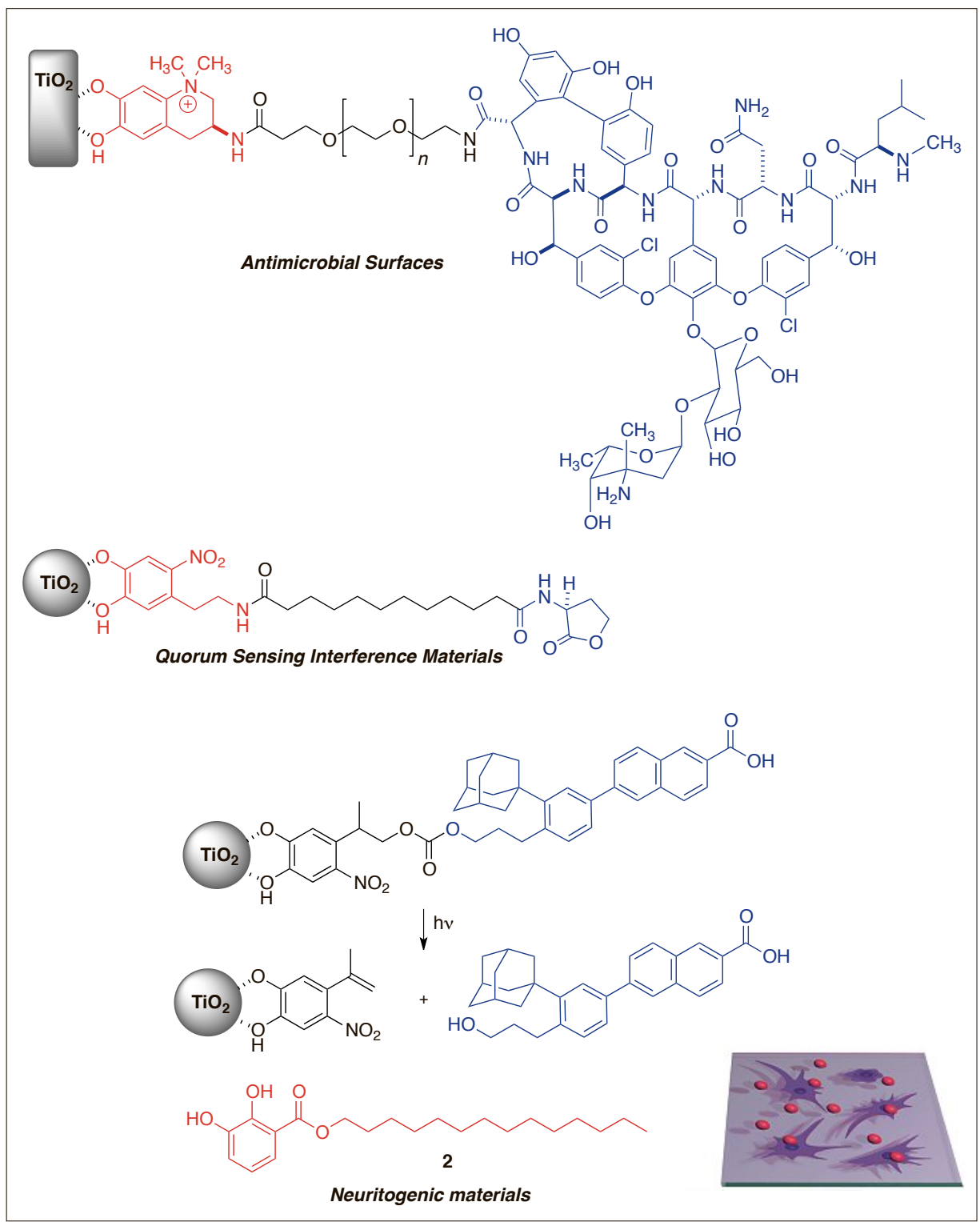

Fig. 11. Catecholate-based natural product hybrids that allow for the generation of antibiotic surface, quorum-sensing interference materials, and neuritogenic materials.

functionality. For instance, ions can passively diffuse or be actively transported through the cytosolic membrane via ion channels or ionic pumps to regulate the transmembrane ionic gradients. As another example, chemical transmitters are used as messengers to carry information between cells and small biomolecules binding channels, enzymes or DNA to regulate the cell molecular activity. The artificial molecular factories that will be engineered within the NCCR MSE will mimic living cells and make use of the same biological mechanisms to obtain the desired functionality. Complex reactions will be confined within smart artificial membranes, which will form a network of individual and interconnected compartments. In order to test, characterize and adjust the activity of such complex molecular systems, a label-free, high sensitivity and miniaturized analytical sensor is highly desirable. In the past years, we have developed Ion-Selective
Field-Effect Transistors (ISFETs) biosensors based on Silicon-Nanowires (SiNWs) to measure local ionic and biomarker concentrations in physiological conditions. We discuss here how we can combine our unique sensing platform with different molecular modules to assess ionic and molecular transport processes through artificial membranes and the behavior of molecular factories. Ultimately, the goal is to monitor cross-communications between molecular systems to provide a feedback mechanism able to regulate biochemical processes.

First introduced by P. Bergveld in the $1970 s,{ }^{[53]}$ the ISFET is historically referred to as a $\mathrm{pH}$ sensor but recent research advances suggest that ISFET-based biosensors may be a valuable approach for the detection of relevant biomarkers. ${ }^{[54-59]}$ due to their high sensitivity, ${ }^{[60,61]}$ ease of use, and potential scalability. ${ }^{[62]}$ At the core of the ISFET lies the principle of the classical Metal-Oxide Semiconductor Field 
Effect Transistor (MOSFET) except that the metallic gate electrode is replaced by a reference electrode (saturated $\mathrm{AgCl}$ or calomel electrode) in solution (Fig. 12a). It is therefore a three-terminal device (drain, source, gate), where the reference electrode is used to apply a gate potential and to modulate the conductance of a semiconducting channel. For a p-type Silicon Nanowire ISFET, applying a negative gate voltage creates an accumulation of charge carriers in the channel and increases its conductance. Biosensing with ISFETs is based on the physisorption or chemisorption of charged molecules at the sensor's surface, which leads to a modification of the surface potential and of the effective gate potential. The additional gating caused by charges can be measured as a shift in the ISFET's transfer characteristic (Fig. 12b). For ISFET-based $\mathrm{pH}$ sensors, high- $\kappa$ dielectric layers, such as $\mathrm{Al}_{2} \mathrm{O}_{3}$, $\mathrm{HfO}_{2}$ or $\mathrm{Ta}_{2} \mathrm{O}_{5}$ are typically used due to their intrinsic $\mathrm{pH}$ sensitivity. Such gate oxide layers exhibit a high density of surface hydroxyl groups, which can undergo protonation and deprotonation in aqueous solutions and yield either a positively or negatively charged surface depending on the solution $\mathrm{pH}$. We have shown that using $\mathrm{HfO}_{2}$ and $\mathrm{Al}_{2} \mathrm{O}_{3}$ oxide, $\mathrm{pH}$ responses at the Nernst limit (the theoretical maximum change of surface potential per $\mathrm{pH}$ unit, $\sim 60 \mathrm{mV} / \mathrm{pH}$ at room temperature, Fig. 12b) can be obtained. ${ }^{[61]}$ Another advantage of high- $\kappa$ oxides as sensing materials is their ability to prevent leakage currents or ionic diffusion through the gate oxide, which can lead to sensor drift and potentially to an electrical failure of the gate oxide. To date, ISFET devices have been proved to be highly sensitive and low noise $\mathrm{pH}$ sensors that can be used for numerous biological applications. Besides $\mathrm{H}^{+}$environmental monitoring, $\mathrm{H}^{+}$detection can be an effective way for the indirect monitoring of enzymatic reactions or metabolic pathways where acidic (or basic) species are either consumed or released as byproducts. The ion semiconductor DNA sequencing for instance takes advantage of the release of protons when a new base is incorporated during DNA replication to perform DNA sequencing. ${ }^{62]}$

For the direct detection of analytes using ISFET sensors, i.e. the detection of charged molecules in solution, the gate oxide surface needs to be engineered such that only the targeted species can bind to the sensor surface. A first approach consists in the covalent or non-covalent functionalization of the SiNWs surface with highly selective receptors, such as DNA or RNA oligomers, antibodies, enzymes or any molecule complementary to the analyte. Self-Assembled Monolayers (SAMs) are often the preferred method to
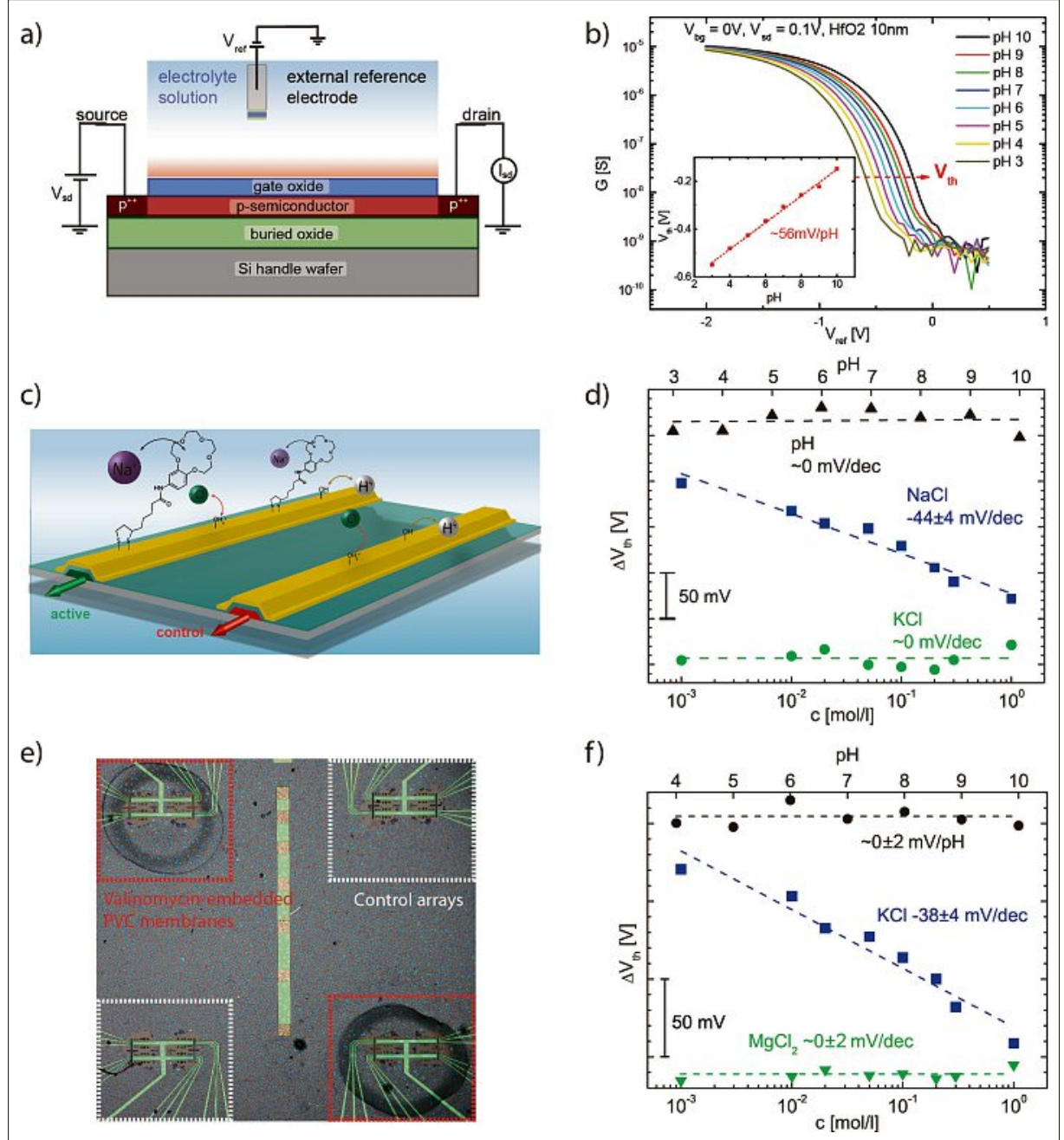

Fig. 12. Biosensing using silicon nanowires ISFETs. a) Cross section of a p-type SiNWs ISFET fabricated by a top-down approach with implanted contacts. A constant source-drain voltage $V_{s d}$ is applied. A back gate voltage $V_{b g}$ and a liquid gate voltage $V_{\text {ref }}$ at the reference electrode are applied. The current $I_{s d}$ through the nanowire is measured. b) Transfer-curves at different $\mathrm{pH}$ (conductance $G$ vs. liquid gate potential $V_{\text {ref }}$ ) of a SiNW with $\mathrm{HfO}_{2}$ as gate oxide. The shift to the right with increasing $\mathrm{pH}$ is quantified by reading out the threshold voltage $V_{\text {th }}$ as the value of $V_{\text {ref }}$ at an arbitrary conductance $G=20$ nS. c) Detection of sodium ions in a differential setup using functionalized gold-coated SiNWs. Active wires are functionalized with $\mathrm{Na}^{+}$receptors while control wires are not. d) Differential threshold voltage $\left(\Delta V_{\text {th }}=V_{\text {thactive }}-V_{\text {th.control }}\right)$ vs electrolytes concentration and $\mathrm{pH}$. Specific contributions can be distinguished from non-specific contributions (e.g. $\mathrm{pH}$ changes, $\mathrm{Cl}^{-}$adsorption, etc.) to reveal a sensitivity of $44 \mathrm{mV} / \mathrm{dec}$ to $\left[\mathrm{Na}^{+}\right]$but no sensitivity to $\left[\mathrm{K}^{+}\right]$. e) $\mathrm{K}^{+}$sensing using selective membranes and SiNWs ISFET. Optical image showing two arrays of SiNWs covered with valinomycin-embedded PVC membranes and two other uncovered arrays used as a control. f) The differential response of the sensor reveals a sensitivity to $\left[\mathrm{K}^{+}\right]$of $38 \mathrm{mV} / \mathrm{dec}$ but no sensitivity to $\left[\mathrm{Mg}^{2+}\right]$.

functionalize oxide (using silanes) or gold layers (using thiols) because SAMs offer a high stability and reproducibility and usually result in a high density of functional groups at the sensor surface. An alternative approach consists in a functionalization based on selective membranes, which can trap molecules or act as a diffusion barrier, i.e. only allow the passive diffusion of specific species to the sensor surface. The ISFET sensor is therefore a powerful tool to assess binding kinetics, ${ }^{[63]}$ ligand-receptor affinities or simply to monitor analyte concentration.

Recently, we have demonstrated the selective sensing of species other than protons using SiNWs decorated with ionic receptors for $\mathrm{Na}^{+}{ }^{[59]} \mathrm{K}^{+},{ }^{[64]} \mathrm{Ca}^{2+[65]}$ and $\mathrm{F}^{-} .{ }^{[66]}$ For this purpose, the dielectric layer of SiNWs is coated with an additional thin gold layer to take advantage of gold chemistry and engineer the surface with self-assembled monolayers of thiol-terminated functional molecules. To provide sensitivity to the targeted species, we respectively use a 15 -crown- $5 \mathrm{Na}^{+}$ligand, an 18-crown- $6 \mathrm{~K}^{+}$ligand, a $\mathrm{F}^{-}$specific ruthenium complex and a 4-carboxyl terminated $\mathrm{K}^{+}$receptor. Our approach includes advanced surface functionalization chemistry along with a sophisticated microfluidic system to achieve a differential setup with specifically functionalized SiNWs and control nanowires on a single 
chip (Fig. 12c). It is important to emphasize that competing contributions to the surface potential changes have to be taken into account (e.g. $\mathrm{pH}$ change, $\mathrm{Cl}^{-}$adsorption, etc.). ${ }^{[65]}$ By using non-functionalized, bare gold nanowires along with selective wires, we are able to distinguish the contribution of $\mathrm{pH}$ or non-specific adsorption from the contribution of the target analytes $\left(\Delta \mathrm{V}_{\text {th }}=\mathrm{V}_{\text {th,selective }}-\mathrm{V}_{\text {th,control }}\right)$, and therefore to build an ISFET-based biosensor (Fig. 12d). Using such a differential approach, we achieved sensitivities of $44 \mathrm{mV} / \mathrm{dec}$ for $\mathrm{Na}^{+}, 33 \mathrm{mV} / \mathrm{dec}$ for $\mathrm{K}^{+}, 12 \mathrm{mV} / \mathrm{dec}$ for $\mathrm{F}^{-}$ and $20 \mathrm{mV} / \mathrm{dec}$ for $\mathrm{Ca}^{2+}$. ${ }^{66]}$

The fact that the measured sensitivities are below the Nernst limit can be attributed to the reduced surface density of functional groups. Using a site-binding model, ${ }^{[67,68]}$ we estimate a surface density of active groups reaching about $1 \%$. It is also crucial to mention the importance of the Debye length, the distance over which a point charge is screened by counter-ions, when performing such measurements. When using ionic receptors anchored to the surface through a linker, the analyte charges will be partially or fully screened if located at or further than the Debye length. In physiological conditions, screening will already take place at nm distances. ${ }^{[69]}$ Where possible, moderate ionic strength solutions will therefore help to improve the sensor signal.

We also demonstrated the detection of potassium ions using selective membranes covering an array of SiNWs. ${ }^{[64]}$ We used sensors with 4 spatially separated arrays of 12 nanowires, where 2 arrays were functionalized with a membrane and 2 arrays were left as is and used as controls in a differential setup (Fig. 12e). For the selective membranes, we used a $\mathrm{K}^{+}$ionophore, valinomycin, embedded in polyvinyl chloride (PVC). Even though we showed that the membrane was permeable to $\mathrm{Cl}^{-}$and $\mathrm{H}^{+}$ions, we could reveal a sensitivity to $\mathrm{K}^{+}$of $38 \mathrm{mV} / \mathrm{dec}$ by subtracting the background response of the control wires to the response of the functionalized wires (Fig. 12f). In a control experiment, we showed that the sensor was not sensitive to $\mathrm{Mg}^{2+}$.

We are currently investigating the use of ISFET biosensors (BioFETs) for the detection of relevant substrates in solution and for the study of binding affinities and kinetics. We are focusing on the detection of FimH, a bacterial lectin involved in urinary tract infection. FimH is an adhesin expressed at the surface of pathogenic bacteria, such as E. coli, which promotes adhesion to cells and surfaces. It is well known that FimH has a strong binding affinity for carbohydrates and D-mannose in particular. As for ions detection, we used goldcoated SiNWs BioFETs to achieve FimH detection using a thiol terminated D-mannose ligand in a differential setup. Using time-resolved measurement, we see that the SiNWs conductance is highly dependent on FimH concentration. ${ }^{[70]}$ Pursuing our efforts in the study of ligand-receptor interactions, we are also working with F. Stellacci, whose group is working on the design of macromolecular transporters for molecular factories. We functionalized gold-coated SiNWs with a mixed monolayer of two different organic ligands and preliminary cations affinity measurements were performed. We are also collaborating with the group of C. Housecroft for the design of ionic receptors. With C. Palivan and W. Meier, we are investigating the ionic transport properties and functionality of simple molecular systems: artificial membranes deposited on the surface of ISFETs.

The NCCR MSE project constitutes a unique opportunity to expand the application of ISFETs towards the monitoring of more complex systems. Silicon nanoribbons BioFETs have the potential for high multiplexing and integration and therefore constitute a versatile analytical tool for monitoring numerous analytes. On a single chip using arrays of SiNWs, we are now able to monitor the concentration of multiple ions and biomarkers simultaneously and to spatially map the activity of complex systems, such as molecular factories, at the microscale.

\section{Acknowledgements}

We acknowledge the Swiss National Science Foundation as part of the NCCR Molecular Systems Engineering, the University of Basel and the University of Zurich for financial support. M.C., A.F. and R.L.S. gratefully acknowledge the Swiss Nanoscience Institute, Avails Medical, Inc. and the European Commission under the H2020 FET Open project RECORD-IT (664786) for their financial support.

Received: March 22, 2016

[1] B. O'Regan, M. Grätzel, Nature 1991, 353, 737.

[2] C. E. Housecroft, E. C. Constable, Chem Soc. Rev. 2015, 44, 8386.

[3] E. Schönhofer, B. Bozic-Weber, C. J. Martin, E. C. Constable, C. E. Housecroft, J. A. Zampese, Dyes and Pigments 2015, 115, 154.

[4] N. Hostettler, I. A. Wright, B. Bozic-Weber, E. C. Constable, C. E. Housecroft, RSC Adv. 2015, 5, 37906

[5] S. Y. Brauchli, E. C. Constable, C. E. Housecroft, Dyes and Pigments 2015, 113, 447.

[6] S. Y. Brauchli, F. J. Malzner, E. C. Constable, C. E. Housecroft, $R S C A d v$. 2014, 4, 62728 .

[7] A. Lanzilotto, L. A. Büldt, H. C. Schmidt, A. Prescimone, O. S. Wenger, E. C. Constable, C. E. Housecroft, RSC Adv. 2016, 6, 15370.

[8] E. C. Constable, W. Meier, C. Nardin, S. Mundwiler, Chem. Commun. 1999, 1483.

[9] H. Lodish, A. Berk, S. L. Zipursky, P. Matsudaira, D. Baltimore, J. Darnell, 'Molecular Cell Biology', WH Freeman New York, 2000.

[10] M. A. Yildirim, K.-I. Goh, M. E. Cusick, A.-L. Barabási, M. Vidal, Nat. Biotechnol. 2007, 25, 1119.
[11] R. P. Richter, J. L. K. Him, A. Brisson, Mater Today 2003, 6, 32 .

[12] J. Kowal, X. Zhang, I. A. Dinu, C. G. Palivan, W. Meier, ACR Macro Lett. 2014, 3, 59 .

[13] M. Tanaka, E. Sackmann, Nature 2005, 437, 656.

[14] C. G. Palivan, R. Goers, A. Najer, X. Zhang, A Car, W. Meier, Chem. Soc. Rev. 2016, 45, 377.

[15] F. Itel, M. Chami, A. Najer, S. Lörcher, D. Wu, I. A. Dinu, W. Meier, Macromol. 2014, 47 , 7588.

[16] F. Itel, A. Najer, C. G. Palivan, W. Meier, Nano Lett. 2015, 15, 3871.

[17] M. Lomora, M. Garni, F. Itel, P. Tanner, M Spulber, C. G Palivan, Biomater. 2015, 53, 406.

[18] X. Zhang, W. Fu, C. G. Palivan,W. Meier, Sci. Rep. 2013, 3, 2196.

[19] L. Song, M. R. Hobaugh, C. Shustak, S. Cheley, H. Bayley, J. E. Gouaux, Science 1996, 274, 1859.

[20] J. Ł. Kowal, J. K. Kowal, D. Wu, H. Stahlberg, C. G. Palivan, W. P. Meier, Biomater. 2014, 35 7286.

[21] R. G. Anderson, K. Jacobson, Science 2002 296, 1821.

[22] J. Kowal, D. Wu, V. Mikhalevich, C. G. Palivan, W. Meier, Langmuir 2015, 31, 4868.

[23] T. Haefele, K. Kita-Tokarczyk, W. Meier, Langmuir 2006, 22, 1164.

[24] X. Zhang, P. Tanner, A. Graff, C. Palivan, W Meier, J. Pol. Sci, Part A 2012, 50, 2293.

[25] C. Draghici, J. Kowal, A. Darjan, W. Meier, C. G. Palivan, Langmuir 2014, 30, 11660.

[26] E. T. Castellana, P. S. Cremer, Surf. Sci. Rep. 2006, 61, 429

[27] K. Langowska, J. Kowal, C. G. Palivan, W Meier, J. Mater. Chem. B 2014, 2, 4684.

[28] J. Kowal, X. Y. Zhang, I. A. Dinu, C. G. Palivan, W. Meier, ACS Macro. Lett. 2014, 3, 59.

[29] S. Volden, M. H. G. Ese, K. Z. Zhu, M. Yasuda B. Nystrom, W. R. Glomm, Coll. Surf. B 2012, 98, 50 .

[30] Y. Matter, R. Enea, O. Casse, C. C. Lee, J. Baryza, W. Meier, Macromol. Chem. Phys. 2011, 212, 937.

[31] R. Barbey, L. Lavanant, D. Paripovic, N Schuwer, C. Sugnaux, S. Tugulu, H. A. Klok, Chem. Rev. 2009, 109, 5437.

[32] C.G. Palivan, R. Goers, A. Najer, X. Zhang, A Car, W. Meier, Chem. Soc. Rev. 2016, 45, 377.

[33] K. Langowska, C. G. Palivan, W. Meier, Chem. Commun. 2013, 49, 128.

[34] X. Zhang, M. Lomora, T. Einfalt, W. Meier, N. Klein, D. Schneider, C. G. Palivan, Biomater 2016, 89, 79

[35] S. Pennathur, D. K. Fygenson, Lab Chip 2008 8,649 .

[36] Reviews: a) K. Gademann, Acc. Chem. Res. 2015, 48, 731; b) E. A. Crane, K. Gademann, Angew. Chem. Int. Ed. 2016, 55, 3882.

[37] J. E. Spangenberg, M. Ferrer, S. Jacomet, N Bleicher, J. Schibler, Org. Geochem. 2014, 69 , 11.

[38] See, for example this review: S. M. Kraemer, A Butler, P. Borer, J. Cervini-Silva, Rev. Mineral. Geochem. 2005, 59, 53.

[39] Review: K. Gademann, J. Kobylinska, J.-Y. Wach, T. M. Woods, Biometals 2009, 22, 595.

[40] a) S. Zürcher, D. Wäckerlin, Y. Bethuel, B Malisova, M. Textor, S. Tosatti, K. Gademann, J. Am. Chem. Soc 2006, 128, 1064. For the total synthesis, see b) K. Gademann, Y. Bethuel, H Locher, J. Org. Chem. 2007, 72, 8361; c) K. Gademann, Y. Bethuel, Org. Lett. 2004, 6, 4707.

[41] J.-Y. Wach, B. Malisova, S. Bonazzi, S. Tosatti, M. Textor, S. Zuercher, K. Gademann, Chem. Eur. J. 2008, 14, 10579.

[42] B. Malisova, S. Tosatti, M. Textor, K. Gademann, S. Zürcher, Langmuir 2010, 26, 4018. 
[43] S. Saxer, C. Portmann, S. Tosatti, K. Gademann, S. Zuercher, M. Textor, Macromol. 2010, 43 1050.

[44] For recent examples, see: a) P. R. Spycher, H. Hall, V. Vogel, E. Reimhult, Biomater. Sci. 2015 , 3, 94; b) Â. Serrano, S. Zürcher, S. Tosatti, N. D. Spencer, Macromol. Rapid Commun. 2016 , 37, 622; c) X. Ding, G. K. Vegesna, H. Meng, A. Winter, B. P. Lee, Macromol. Chem. Phys. 2015, 216, 1109; d) K. Turcheniuk, M. Khanal, A. Motorina, P. Subramanian, A. Barras, V. Zaitsev, V. Kuncser, A. Leca, A. Martoriati, K. Cailliau, J.-F. Bodart, R. Boukherroub, S. Szunerrits, RSC Adv. 2014, 4, 865.

[45] For examples, see: a) EP2684942A1 to The Swatch Group Research and Development Ltd; b) WO2012159106A2 to Northwestern University.

[46] R. Wehlauch, J. Hoecker, K. Gademann, ChemPlusChem 2012, 77, 1071. See also: Z. Shafiq, J. Cui, L. Pastor-Pérez, V. San Miguel, R. A. Gropeanu, C. Serrano, A. Del Campo, Angew. Chem. Int. Ed. 2012, 51, 4332.

[47] See for reviews: a) B. P. Lee, P. B. Messersmith, J. N. Israelachvili, J. H. Waite, Annu. Rev. Mater. Res. 2011, 41, 99; b) Q. Ye, F. Zhou, W. Liu, Chem. Soc. Rev. 2011, 40, 4244; c) J. Sedó, J. Saiz-Poseu, F. Busqué, D. Ruiz-Molina, $A d v$. Mater. 2012, 25, 653.

[48] J.-Y. Wach, S. Bonazzi, K. Gademann, Angew. Chem. Int. Ed. 2008, 47, 7123.

[49] a) J. Gomes, A. Grunau, A. K. Lawrence, L. Eberl, K. Gademann, Chem. Commun. 2013, 49, 155; b) J. Gomes, N. Huber, A. Grunau, L. Eberl, K. Gademann, Chem. Eur. J. 2013, 19 9766; c) J. Gomes, A. Grunau, A. K. Lawrence, L. Eberl, K. Gademann, Chimia 2013, 67, 275.

[50] J. Hoecker, R. Liffert, P. Burch, R. Wehlauch, K. Gademann, Org. Biomol. Chem. 2013, 11, 3314.
[51] P. Burch, F. Schmid, K. Gademann, $A d v$. Healthcare Mater. 2014, 3, 1415.

[52] J. Ruschel, F. Hellal, K. C. Flynn, S. Dupraz, D. A. Elliott, A. Tedeschi, M. Bates, C. Sliwinski, G. Brook, K. Dobrindt, M. Peitz, O. Brüstle, M. D. Norenberg, A. Blesch, N. Weidner, M. Bartlett Bunge, J. L. Bixby, F. Bradke, Science 2015, 348, 347.

[53] P. Bergveld, IEEE Trans. Biomed. Engin. 1970, 17, 70 .

[54] Y. Cui, Y. Cui, Q. Wei, H. Park, C. M. Lieber, Science 2001, 293, 1289.

[55] A. Gao, N. Lu, Y. Wang, P. Dai, T. Li, X. Gao, Y. Wang, C. Fan, Nano Lett. 2012, 12, 5262.

[56] E. Stern, A. Vacic, N. K. Rajan, J. M. Criscione, J. Park, B. R. Ilic, D. J. Mooney, M. A. Reed, T. M. Fahmy, Nat. Nanotechnol. 2010, 5, 138.

[57] E. Stern, J. F. Klemic, D. A. Routenberg, P. N. Wyrembak, D. B. Turner-Evans, A. D. Hamilton, D. A. LaVan, T. M. Fahmy, M. A. Reed, Nature 2007, 445, 519.

[58] G. Zheng F. Patolsky, Y. Cui, W. U. Wang, C. M. Lieber, Nat. Biotechnol. 2005, 23, 1294.

[59] M. Wipf, R. L. Stoop, A. Tarasov, K. Bedner, W. Fu, I. A. Wright, C. J. Martin, E. C. Constable, M. Calame, C. Schönenberger, ACS Nano 2013, 7, 5978.

[60] S. Chen, J. G. Bomer, E. T. Carlen, A. van den Berg, Nano Lett. 2011, 11, 2334.

[61] O. Knopfmacher, A. Tarasov, W. Fu, M. Wipf, B. Niesen, M. Calame, C. Schönenberger, Nano Lett. 2010, 10, 2268.

[62] J.M. Rothberg, W. Hinz, T. M. Rearick, J. Schultz, W. Mileski, M. Davey, J. H. Leamon, K. Johnson, M. J. Milgrew, M. Edwards, J. Hoon, J. F. Simons, D. Marran, J. W. Myers, J. F. Davidson, A. Branting, J. R. Nobile, B. P. Puc, D. Light, T. A. Clark, M. Huber, J. T. Branciforte, I. B. Stoner, S. E. Cawley, M. Lyons, Y. Fu, N. Homer, M. Sedova, X. Miao,
B. Reed, J. Sabina, E. Feierstein, M. Schorn, M. Alanjary, E. Dimalanta, D. Dressman, R. Kasinskas, T. Sokolsky, J. A. Fidanza, E. Namsaraev, K. J. McKernan, A. Williams, G. T. Roth, J. Bustillo, Nature 2011, 475, 348.

[63] X. Duan, Y. Li, N. K. Rajan, D. A. Routenberg, Y. Modis, M. A. Reed, Nat. Nanotechnol. 2012, 7, 401 .

[64] M. Wipf, R. L. Stoop, A. Tarasov, K. Bedner, W. Fu, M. Calame, C. Schönenberger in 2013 Transducers Eurosensors XXVII: The 17 th International Conference on Solid-State Sensors, Actuators and Microsystems. 2013.

[65] R. L. Stoop, M. Wipf, S. Müller, K. Bedner, I. A. Wright, C. J. Martin, E. C. Constable, W. $\mathrm{Fu}$, A. Tarasov, M. Calame, C. Schönenberger, Sensors and Actuators B: Chem. 2015, 220, 500.

[66] R. L. Stoop, M. Wipf, S. Müller, K. Bedner, I. A. Wright, C. J. Martin, E. C. Constable, A. Fanget, C. Schönenberger, M. Calame, Biosensors 2016, 6, 21.

[67] D. E. Yates, S. Levine, T.W. Healy, J. Chem. Soc., Faraday Trans. 1974, 70, 1807.

[68] A. Tarasov, M. Wipf, K. Bedner, J. Kurz, W. Fu, V. A. Guzenko, O. Knopfmacher, R. L. Stoop, M. Calame, C. Schönenberger, Langmuir 2012, 28, 9899.

[69] A. Vacic, J. M. Criscione, N. K. Rajan, E. Stern, T. M. Fahmy, M. A. Reed, J. Am. Chem. Soc. 2011, 133, 13886.

[70] M. Wipf, R. L. Stoop, G. Navarra, S. Rabbani, B. Ernst, K. Bedner, C. Schönenberger, M. Calame, ACS Sens. 2016, DOI:10.1021/ acssensors.6b00089. 